\title{
Input of Chunks and Its Effects on L2 Learners' Listening Competency
}

\author{
Jingwei Tang \\ Shandong Jiaotong University, Jinan, China
}

\begin{abstract}
The study tires to explore the effectiveness of acquisition of chunks to improve L2 learners' listening competency. An empirical study is designed and conducted on the basis of theory of chunks and information processing mode. Analysis of the experimental data shows that acquisition of chunks can effectively help L2 learners to improve their listening competency. Result of the experiment reveals that the number of chunks closely correlates with $\mathbf{L 2}$ learners' listening scores, because chunks can boost $L 2$ learners' efficiency of processing language information and predicate information while listening.
\end{abstract}

Index Terms - chunks, the lexical approach, listening competency, L2 learners

\section{INTRODUCTION}

Listening comprehension is an input process of listeners' processing discourse information passively as well as a course for the listeners to perceive, store, decode and comprehend information. Gilman \& Moody (1984) finds that adults spend $40-50 \%$ of communication time listening. Listening input is an essential component of language input and information input, playing a vital role of facilitating language understanding and learning. However, for many L2 learners in China, listening ability has been the weakness, which has badly influenced their progress in learning a foreign language. Low listening competency is a big obstacle for them to conduct successful communication. In many cases, L2 learners can only capture some discrete words and are unable to notice the whole structure of what speakers say. Low efficient L2 learners focus too much attention on identifying sounds and understanding vocabulary and grammatical structures. Chunks, which focus on the integration of words, are helpful to facilitate L2 learners to comprehend listening materials integrally. The thesis adopts the theory of chunks to explore a way to improve L2 learners' listening competency.

\section{THEORETICAL FRAMEWORKS}

\section{A. Theory of Chunks and the Lexical Approach}

Vocabulary has usually been referred to individual words, but it is evident that much of lexis consists of sequences of words which operate as individual units, with meanings different from separate words. Numerous terms have been coined to refer to this type of sequence: lexical chunks, collocations, prefabricated phrases, formulaic language, lexical bundles etc. In this thesis, "chunks" or "lexical chunks" is adopted and the thesis prefers the definition of "chunks" defined by Wray (2002): "A sequence, continuous or discontinuous, of words or other elements, which is, or appears to be, prefabricated: that is, stored and retrieved whole from memory at the time of use, rather than being subject to generation or analysis by the language grammar.". Altenberg (1998) researches and finds that $80 \%$ of the discourse components are varieties of lexical chunks and chunks, instead of individual words, are the smallest unit to perform the memory, storage, input and output of discourse. Therefore, if L2 learners could master a large number of chunks, it would be much helpful for them to analyze the meanings of what the speakers say. Lexical chunks conventionally fall into the following categories (Lewis, 1997):

- polywords (e.g., by mean of, in this way)

- collocations, or word partnerships (e.g., come to life, be fully justified, heavy traffic jam)

- institutionalized utterances (e.g., It's beyond me; If not for ...; Would you like a cup of coffee?)

- sentence frames and heads (e.g., Some believe that..., others hold that...; The primary reason is that ... ; It goes without saying that...) and even text frames (e.g., In this paper we explore ...; Firstly ...;Secondly ...; Finally ...

Lewis (1993) puts forward "The Lexical Approach" based on theory of chunks. A lexical approach in language teaching refers to one derived from the belief that the building blocks of language learning and communication are not grammar, functions, notions, or some other units of planning and teaching but lexis, that is, words and word combinations. Vocabulary and lexical units are considered the central part and basis of learning and teaching a second language in the lexical approach, as Lewis (1993) says "language consists of grammaticalized lexis, not lexicalized grammar." The lexical approach advocates argue that majority of spoken sentences are not newly created and that Chunks in the form of multi-word units or memorized patterns contribute to the formation of fluent expressions heard in everyday conversation. Lexical approach holds that chunks can efficiently accelerate the speed of processing and generating language. 
Michael Lewis (1993) suggests that the lexical approach is based on the following principles in his book The Lexical Approach: The State of ELT and a Way Forward.

- Language consists of grammaticalized lexis, not lexicalized grammar.

- Structural patterns are acknowledged as useful but lexical patterns are considered of primary importance to language teaching.

- Much language consists of multi-word "chunk".

- Teachers should raise students" awareness of "chunk" and develop their ability to "chunk" language successfully.

- Receptive skills, particularly listening, are recognized as deserving primary importance.

- The present-practice-produce paradigm is rejected in favor of a paradigm based on observe-hypothesis-experiment cycle.

B. Information Processing Mode

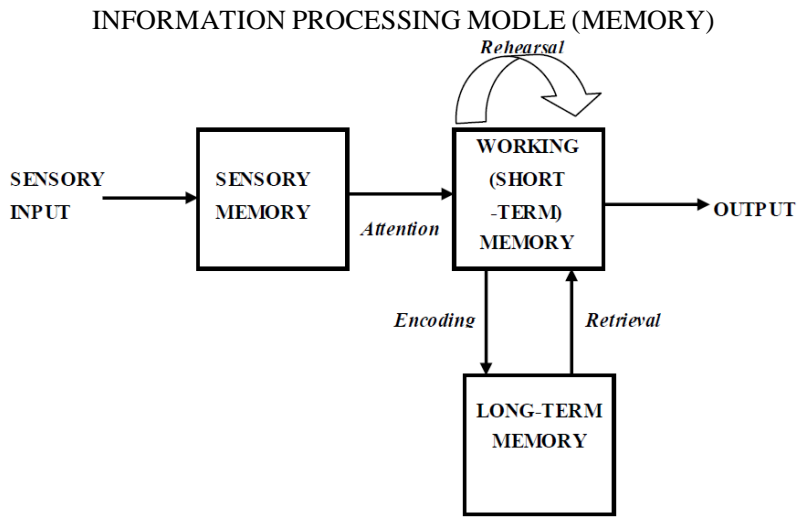

Listening comprehension is a dynamic process, which is composed of two parts: top-down process and bottom-up process. In the top-down mode, listeners use knowledge already stored in the brain (long-term memory) to construct the meanings of language. The knowledge includes topic knowledge, listening context, text-type, culture or other information and establishes a listening schema. Clues in the listening texts can stimulate the schema of listeners and help to better understand the texts. In the other mode, listeners perceive the meanings of listening discourse with linguistic knowledge. The process to construct meaning ways up from sounds to words to grammatical relationships and then to lexical meanings. In the process of listening comprehension, the two ways do not work separately and individually but interactively. Listeners use both knowledge stored in the brain and linguistic knowledge to comprehend messages.

The process of information is as is shown in the following picture. Attention is the only way to have input remembered and it is an essential part of information processing which transforms input into intake. Short-term/ working memory is the center of conscious thought with limited capacity, which makes it impossible to process too much information at a time. Therefore, listeners cannot remember too many units temporarily. If the memory units take the form of chunks instead of individual words, it will definitely help listeners to process more language information. The following picture also shows that rehearsal is the way to convert working memory/ short-term memory to long-term memory. Thereby, when the lexical approach is adopted in L2 teaching and learning process, abundant repetition and practice are necessary and vital to help L2 learners to memorize lexical chunks.

\section{RESARCH QESTIONS}

An empirical study is conducted in the thesis in order to explore the roles of mastering chunks in second language acquisition and effectiveness of the lexical approach in second language listening. The author tries to answer the following questions in this thesis:

1. Does the number of chunks mastered by the L2 learners correlates with their listening abilities?

2. Is the Lexical Approach effective to enhance L2 learners listening competency?

3. How should the Lexical Approach be applied to teaching chunks in second language teaching?

\section{RESEARCH METHOD}

\section{A. Participants}

In spring of 2012, the author chose two parallel classes in Shandong Jiaotong University in China and conducted an empirical study. The experiment lasts two academic semesters. All the participants are sophomores of engineering majors. Before the study, majority of the participants have learned English for at least eight years and the two classes' level of mastering English language proves to be approximately equivalent after an analysis of their scores in the final 
term examination. The two classes take a pre-test and a post-test in the study to check, analyze and compare their levels of English learning competency.

\section{B. Method}

In the study, New College English (Listening and Speaking Course) is chosen as the text books in the two classes. The lexical method was adopted to focus on the input of lexical chunks and a communicative approach is accompanied in the teaching process in the experimental class. Initiator of the lexical approach, Lewis, (1993) doesn't negate the effectiveness of communicative approach in second language teaching. Instead, he argues that the Lexical Approach is the supplement and advancement of communicative approach. For the reference class, the conventional communicative teaching method is employed with the same text books. Data of the study stems from a pre-test and a post-test, and SPSS17.0 is used for statistics and analysis.

\section{Process}

1. Recognizing Chunks and Cultivating Awareness of Chunks.

An essential learning strategy is to teach and train students to recognize and notice chunks when they are exposed to the listening discourse. The conventional way to teach listening in L2 teaching is to play tapes repeatedly and focuses too much on requiring students to fix their attention on separate syllables, words and sentences. After being able to identify chunks, students should be guided to raise their awareness of using chunks and learn to base their listening comprehension on the combination of chunks with the context. As what is discussed in II (B), attention is the only way to memory. Attention to the chunks is necessary on the way to store language knowledge and establish schema. Recognizing and mastering chunks of listening discourse can lighten the memory burden of students and guide them to comprehend the listening materials integrally.

2. Practicing and Analyzing Chunks.

Some activities should be designed and developed to help students to notice and practice chunks in the course of perform listening. Improvement of listening is a step-by-step process. Thereby, acquisition of chunks should be advanced gradually. In the beginning period, teachers can play only two or three sentences and then ask students to write down the chunks they hear. Subsequently, teachers ask students to collect chunks and analyze them so as to understand the structure of chunks, what they mean and how they are used. In this way, students can obtain a global understanding of the structure of the chunks. Teachers also have students note down chunks out of class and review them afterwards.

3. Consolidating the Mastering of Chunks.

In the wake of the practice above, students have established their awareness of chunks and endowed themselves with the abilities of identifying and practicing chunks. Teachers come to require students to write complete sentences including chunks while listening to the text. Students are guided to concentrate more on the chunks and the context in this procedure.

\section{Data Collection}

Measurement instruments of the study are two listening passages, one with 286 words and the other with 279 words. The two listening passages are played separately in the pre-test and post-test. Each passage is played for three times and students are asked to write down what they hear.

1. The two passages are played regularly in the first and third listening. The audio file played in the second listening is reproduced with software Cool Edit Pro 2.1. Interval between every two sentences is extended according to the length of the sentences so that students have enough time to write down what they hear.

According to the rules of identification and classification put forward by Lewis (1993\&1997), chunks in the passages of the pre-test and the post-test are picked out, with the number 56 and 51separately.

2. T-unit measure is also introduced in this study. T-unit is a term coined by Hunt Kellogg (1965), as is defined as the "shortest grammatically allowable sentences into which (writing can be split) or minimally terminable unit." In linguistic research, T-unit is applied to analyzing the complexity of sentences and maturity of following grammar rules. T-unit is often, but not always, a sentence. In the study, T-unit is used to assess the levels of participants to follow grammar rules correctly and measure the degree of participants' abilities to capture what the speakers say.

3. Manuscripts of the participants are scored by three researchers and a mean score is adopted for each. Scores of the participants are processed with SPSS 17.0.

\section{DataAnalysis And Results}

Some descriptive and inferential statistical procedures are started to assess the effect of the study. Number of T-units and chunks are compared between the experimental class and the reference class. 
TABLE 1

INDEPENDENT SAMPLES TEST OF RESULTS OF POST-TEST (CHUNKS)

\begin{tabular}{|l|l|l|l|l|l|l|}
\hline & Group & Min. & Max. & Mean & t & Sig. (2-tailed) \\
\hline \multirow{2}{*}{ Post-test } & Experimental Class & 4 & 38 & 28.24 & \multirow{2}{*}{0.214} & \multirow{2}{*}{0.016} \\
\cline { 2 - 5 } & Reference Class & 2 & 37 & 22.38 & \\
\hline
\end{tabular}

TABLE 2

INDEPENDENT SAMPLES TEST OF RESULTS OF POST-TEST (T-UNITS)

\begin{tabular}{|l|l|l|l|l|l|l|}
\hline & Group & Min. & Max. & Mean & t & Sig. (2-tailed) \\
\hline \multirow{2}{*}{ Post-test } & Experimental Class & 3 & 18 & 11.12 & \multirow{2}{*}{0.136} & \multirow{2}{*}{0.023} \\
\cline { 2 - 5 } & Reference Class & 0 & 17 & 7.36 & \\
\hline
\end{tabular}

As Table 1 indicates, number of the chunks written down by the experimental class far exceeds the number of those written down by the reference class after two semesters' experiment. The two groups of data are significantly different at the level of $0.016(<0.05)$. The most probable explanation to the difference is that the lexical approach is highly effective to improve L2 learner's abilities of acquiring chunks. Table 2 shows that the experimental class can write down much more T-units in the post-test. T-unit is also a way to measure L2 learners' degree of mastering grammar rules. Therefore, Table 2 also means that acquisition of chunks is effective to help L2 learners to improve their abilities of applying grammar rules and organizing sentences correctly.

TABLE 3

RESULT AND COMPARISON OF THE TWO TESTS

\begin{tabular}{|l|l|l|l|l|l|}
\hline Test & Class & Mean & MD & t & Sig. \\
\hline \multirow{2}{*}{ Pre-test } & Reference Class & 12.822 & \multirow{2}{*}{0.037} & \multirow{2}{*}{0.021} & \multirow{2}{*}{0.591} \\
\cline { 2 - 6 } & Experimental Class & 12.859 & & \multirow{2}{*}{0.006} \\
\cline { 2 - 3 } Post-test & Reference Class & 13.426 & 2.373 & \multirow{2}{*}{3.274} & \\
\cline { 2 - 3 } & Experimental Class & 15.799 & & \\
\hline
\end{tabular}

A major premise of the research test is that the subjects do not show significantly different levels of listening competency. The pre-test has confirmed this and guaranteed the premise. After two semesters' teaching chunks with the lexical approach, the subjects in the two classes perform substantially differently on the level of listening competency. As is shown in Table 3, the mean deviation between the two classes becomes greater in the post-test, with the P value $0.006<0.05$. With other variables under control, different teaching methods may be the probable factor to account for the difference.

Although Table 3 indicates that students in the experimental class have greatly improved their listening abilities, a question still remains to be answered, that is, does the improvement correlate with the mastering of chunks? In order to find out the answer, a correlation analysis is conducted. Table 4 reveals the relation between the number of chunks and the students listening scores: a close positive correlation, which means that the more chunks students master, the more scores they may achieve in the listening tests.

TABLE 4

CORRELATION BETWEEN THE NUMBER OF CHUNKS AND LISTENING SCORES

\begin{tabular}{|l|l|l|l|}
\hline & & Number of Chunks & Score \\
\hline \multirow{2}{*}{ Number of Chunks } & Pearson Correlation & 1.00 & $0.712^{* *}$ \\
\cline { 2 - 5 } & Sig.(2-tailed) &. & 0.000 \\
\hline \multirow{2}{*}{ Score } & Pearson Correlation & $0.712^{* *}$ & 1.00 \\
\cline { 2 - 5 } & Sig.(2-tailed) & 0.000 &. \\
\hline
\end{tabular}

\section{DISCUSSION}

From the results of the empirical study, a conclusion can be conducted that teaching chunks with the lexical approach can effectively enhance students' listening competency.

\section{A. Chunks Are Helpful to Increase L2 Listeners' Efficiency of Processing Language while Listening}

Acquisition of language is base on two modes: rule-based mode and exemplar-based mode. The rule-based system is adopted when there is enough time to process language and much accuracy is required, while the exemplar mode is in need when communication is conducted in limited time but under sufficient context. The exemplar mode can reduce the burden of brain to process language and decrease the time to react. Meanwhile, the brain processes language with the unit of chunks, a sequence of words, instead of processing language in the form of individual words, which can efficiently decrease the speed of language processing, which is of great significance in the process of a second language listening. As the diagram in II (B) indicates, the short-term memory needs to encode information to convert to long-term information. Language information in the form of fewer chunks rather than the form of more individual words can definitely be of favor to help L2 learners memorize language items. Given the time emergency of processing language, chunks are more favorable to help L2 learners to improve their listening competency. 


\section{B. Acquisition of Chunks can Help L2 Listeners to Improve Their Predictive Abilities while Listening}

It's no wonder good predicative abilities are essential for L2 listeners to catch information from the listening materials. Mastering sufficient chunks can help L2 listeners cultivate their predictive abilities while listening, since chunks are endowed with pragmatic functions. In the course of speech communication, what language users choose are not individual words but chunks with pragmatic functions: social interaction, necessary topics and discourse device. (Nattinger\& DeCarrico, 1992) In other words, chunks is of use for organizing discourse, connecting information and indicating information. Chunks are important means of textual cohesion, which can help L2 listeners, better understand the relation among paragraphs and the overall structure of listening discourses.

\section{Teaching Chunks Appropriately can Help L2 Learners to Boost Their Listening Competency}

The study has found that the number of chunks correlates with L2 learners' listening abilities. L2 learners need to increase the input of chunks and improve their abilities of acquiring chunks. Sufficient input of chunks can enrich the storage of language information. The INFORMATION PROCESSING MODE in II (B) shows attention is a vital step on the way to memory, which requires L2 learners to learn to identify chunks. It also indicates that rehearsal and retrieval are essential to process language and transform language input into language output, which means that adequate practice of using chunks are important to booster L2 learners' language application abilities including their listening competency.

\section{Acquisition of Chunks can Help L2 Learners Build up Their Self-confidence while Listening}

Acquisition of chunks can help the learners lighten the burden of memory, reducing the difficulty of learning a foreign language. Pragmatic function of chunks can guide learners to allocate more attention on the context of communication, which contributes to the fluency of speaking a foreign language and reduces the time to react. All of these can help L2 learners to endow themselves with more confidence and keep calmer during communication, which is a guarantee of a successful communication.

\section{CONCLUSION}

Chunks are important components of language as well as an effective way to learn a foreign language. L2 learners should focus attention of the usage and functions of chunks and master chunks by adopting appropriate chunk acquisition strategies. L2 teachers should also emphasize the lexical approach to teach chunks and help L2 learners to enhance their language application abilities.

Limitation of the study seems to be inevitable. The study has proved that the acquisition of chunks does help the L2 learners improve their listening competency. However, the subjects of the experiment are only confined to the range of non-English majors with low level of learning English. Can it also be applied to helping the English majors with high level of learning English effectively? Is acquisition of chunks helpful for the L2 learners to improve their abilities of speaking, writing and reading? In what degree can acquisition of chunks work to help the L2 learners? All of the above still remain to be experimented and studied? Accumulation of chunks is essential to L2 learning, but it is only a part of the process to learn a language and it not the only indicator to decide the success of language learning. The study on the roles of mastering chunks still remains to be developed further.

\section{ACKNOWLEDGMENT}

This work was supported in part by a grant from Scientific Research Program of Shandong Jiaotong University with the grant No. R201202. The thesis is one of the findings of the author's series study on chunks and the lexical approach. The author's thanks also go to Educational Department of Shandong Province who offers the author a chance to conduct an overseas study in America which makes the research reference more accessible and convenient.

\section{REFERENCES}

[1] Altenberg, B. (1998). On the Phraseology of Spoken English: the Evidence of Recurrent Word Combinations. In A. P. Cowie (Ed.), Phraseology: Theory, Analysis and Applications, 101-122. Oxford: Oxford University Press.

[2] Altenberg, B. \& Granger, S. (2001). The Grammatical and Lexical Patterning of "make" in Native and Non-native Student Writing. Applied Linguistics, 22,173- 194.

[3] Boers, F et al. (2006). Formulaic Sequences and Perceived Oral Proficiency: Putting a Lexical Approach to the Test. Language Teaching Research, 10, 245-261.

[4] Cowie, A. P. (1998). Phraseology: Theory, Analysis, and Applications. Oxford: Oxford University Press.

[5] Chen Yan, (2010). Correlation between the Acquisition of Chunks and Oral Communication Competency. Journal of Shandong Foreign Language Teaching, 2, 38-42.

[6] Conklin, K. \& Schmitt, N. (2008). Formulaic Sequences: Are They Processed More Quickly than Non-formulaic Language by Native and Nonnative Speakers? Applied Linguistics, 29, 72-89.

[7] Ellis R. (1999). The Study of Second Language Acquisition. Shanghai: Shanghai Foreign Languages Education Press.

[8] Ellis, N. \& Simpson-Vlach, R. et al. (2008). Formulaic Language in Native and Second Language Speakers: Psycho-linguistics, Corpus Linguistics, and TESOL. TESOL Quarterly, 42, 375-396. 
[9] Gilman, R. A. \& L. M. Moody (1984). What Practitioners say about Listening: Research Implications for the Classroom. Foreign Language Annals, 17, 331-34.

[10] Girard, M. \& Sionis, C. (2004). The Functions of Formulaic Speech in the L2 Class. Pragmatics, 14, $31-53$.

[11] Hunt, Kellogg W. (1965). Grammatical Structures Written at Three Grade Levels. Champaign, IL: National Council of Teachers of English.

[12] Krashen S D. \& R Scarcella. (1978). On Routines and Patterns in Language Acquisition and Performance. Language Learning, $12,283-300$.

[13] Lewis, M. (1997). Implementing the Lexical Approach: Putting Theory into Practice. England: Language Teaching Publications.

[14] Lewis, M. (1993). The Lexical Approach. England: Language Teaching Publications.

[15] Lewis, M. (2000). Language in the Lexical Approach. In M. Lewis, Teaching Collocation: Further Developments in the Lexical Approach. Hove: Language Teaching Publications.

[16] Liao, Yan \& Y. Fukuya. (2004). Avoidance of Phrasal Verbs: The Case of Chinese Learners of English. Language L earning, $54,193-226$.

[17] Nattinger, J. R. \& De Carrico, J. S. (1992). Lexical Phrases and Language Teaching. London: Oxford University Press.

[18] Nesselhaluf, N. (2003). The Use of Collocations by Advanced Learners of English and Some Implications for Teaching. Applied Linguistics, 24, 223- 242.

[19] O’Malley, J. M. \& A. U. Chamot. (1990). Learning Strategies in Second Language Acquisition. Cambridge: Cambridge University Press.

[20] Pawley, A. \& F. H. Syder. (1983). Two Puzzles for Linguistic Theory: Nativelike Selection and Nativelike Fluency. In J. C. Richards \& R. W. Schmidt, Language and communication. London: Longman, 191-225.

[21] Richard C. Atkinson \& Richard Shiffrin. (no date). Information Processing Theory. http://en.wikipedia.org/wiki/Information_processing_theory (accessed 06/01/2012).

[22] Schegloff, E. A., I. Koshik, S. Jacoby \& D. Olsher. (2002). Conversation Analysis and Applied Linguistics. Annual Review of Applied Linguistics 22, 3-31.

[23] Sinclair, J. \& A. Renouf. (1988). A Lexical Syllabus for Language Learning. In R. Carter \& M. McCarthy, Vocabulary and Language Teaching. London: Longman.

[24] Skehan, P. (1998). A Cognitive Approach to Language Learning. Shanghai: Shanghai Foreign Language Educational Press.

[25] Swales, J. M. (1990). Genre Analysis: English in Academic and Research Settings. London: Cambridge University Press.

[26] Thomas, J. (1983). Cross-cultural Pragmatic Failure. Applied Linguistics, 4, 91-112.

[27] Wang Lifei \& Zhang Yan. (2006). An Overview of Study on Chunks in ESL Abroad, Foreign Language Teaching, 3, 45-49.

[28] Williams, M. (1988). Language Taught for Meetings and Language Used in Meetings: Is There Anything in Common? Applied Linguistics, 9.1, 45-58.

[29] Willis, J. (1998). Concordances in the Classroom without a Computer: Assembling and Exploiting Concordances of Common Words. In B. Tomlinson, Materials Development in Language Teaching. London: Cambridge University Press.

[30] Wray, A. (1999). Formulaic Language in Learners and Native Speakers. Language Teaching, 32.4, $213-31$.

[31] Wray, A. (2000). Formulaic sequences in second language teaching: principle and practice. Applied Linguistics, 21.4, 463-89.

[32] Wray, A. \& Perkins M.R. (2000). The Functions of Formulaic Language: An Integrated Model. Language and Communication, $20.1,1-28$

[33] Yu Xiulian. (2008). An Experimental Study on the Lexical Approach to Improving English Language Competency. World of Foreign Languages, 3, 54-61.

[34] Zeng Qingmin. (2012). Lexical Chunks and Their Effects on Developing English Listening Competency. Journal of Chongqing Industry and Business University, 4, 135-139.

Jingwei Tang, born in Linyi, China in 1977. He received his M.A from Shandong University.

He is currently a Lecturer in the School of Foreign Languages, Shandong Jiaotong University, Jinan, China. His research interests include second language acquisition and pragmatics. Jingwei Tang now works as a visiting scholar conducting ESL research in America at present. 